\title{
MORPHOLOGICAL CHANGES ALONG A DIKE LANDSIDE SLOPE SAMPLED BY 4D HIGH RESOLUTION TERRESTRIAL LASER SCANNING
}

\author{
Mónica Herrero-Huerta ${ }^{a^{*}}$, Roderik Lindenbergh ${ }^{\mathrm{a}}$, Luc Ponsioen $^{\mathrm{b}}$ and Myron van Damme ${ }^{\mathrm{b}}$ \\ ${ }^{a}$ Department of Geoscience and Remote Sensing, Delft University of Technology, 2628 CN Delft, The Netherlands - \\ (m.herrerohuerta, r.c.lindenbergh)@ tudelft.nl \\ ${ }^{\mathrm{b}}$ Department of Hydraulic Structures and Flood Risk, Delft University of Technology, 2628 CN Delft, The Netherlands -
} m.vandamme@tudelft.nl

Commission III, WG III/2

KEYWORDS: Terrestrial laser scanner, morphological changes, dike landside slope, erosion and deposition, hydrogeological models, LiDAR.

\begin{abstract}
:
Emergence of light detection and ranging (LiDAR) technology provides new tools for geomorphologic studies improving spatial and temporal resolution of data sampling hydrogeological instability phenomena. Specifically, terrestrial laser scanning (TLS) collects high resolution 3D point clouds allowing more accurate monitoring of erosion rates and processes, and thus, quantify the geomorphologic change on vertical landforms like dike landside slopes. Even so, TLS captures observations rapidly and automatically but unselectively.

In this research, we demonstrate the potential of TLS for morphological change detection, profile creation and time series analysis in an emergency simulation for characterizing and monitoring slope movements in a dike. The experiment was performed near Schellebelle (Belgium) in November 2015, using a Leica Scan Station C10. Wave overtopping and overflow over a dike were simulated whereby the loading conditions were incrementally increased and 14 successful scans were performed. The aim of the present study is to analyse short-term morphological dynamic processes and the spatial distribution of erosion and deposition areas along a dike landside slope. As a result, we are able to quantify the eroded material coming from the impact on the terrain induced by wave overtopping which caused the dike failure in a few minutes in normal storm scenarios $(\mathrm{Q}=25 \mathrm{l} / \mathrm{s} / \mathrm{m})$ as $1.24 \mathrm{~m}^{3}$. As this shows that the amount of erosion is measurable using close range techniques; the amount and rate of erosion could be monitored to predict dike collapse in emergency situation.

The results confirm the feasibility of the proposed methodology, providing scalability to a comprehensive analysis over a large extension of a dike (tens of meters).
\end{abstract}

\section{INTRODUCTION}

Survey data acquisition has been revolutionized by recent developments in technology, allowing new perceptions on detailed structure detection of the surface. These advances have had a profound impact on the practice of hydrogeology, reducing the economic costs, the time requirements and estimation errors. Thereby, TLS instruments, which rely on LiDAR technology, can scan large fields of view, fast producing an accurate full 3D point cloud with a high density. In addition, such a 'noncontact' measurement technique reduces potential risks and does not alter the surface of interest. In contrast to digital photogrammetry, recent research affirms that TLS data capture very fine scale variations ( $\mathrm{mm}$ level) in surface elevation with more detail (Aguilar et al., 2009). On the other hand, morphological change detection in terrain is essential to notice failure mechanisms, deriving deformation pattern predictions and sliding surface features. These studies are vital to effectively plan active and passive defence systems for risk mitigation.

Deformation field estimations through 3D data has been analysed by several authors. Caelli et al. (1998) studied 3D matching to determine defect objects using geometric features and relational learning. In surface deformation, a good review of the used methods to match multi-temporal 2.5D images was compiled by Sutton et al. (2009). Regarding landside areas, Ujike and Takagi (2004) presented a least squares method in 3D match objects. The detection of landslide displacement fields through an approach based on the Iterative Closest Point (ICP) algorithm was introduced by Teza et al. (2007). Retrogressive and rotational landslides in river banks from digital elevation models (DEMs) coming from TLS were studied by Jaboyedoff et al., (2009). Furthermore, erosional processes and morphodynamic changes were investigated using TLS technology. A method to evaluate the hard rock coastal cliff erosion between triangulated models was considered by Rosser et al. (2005). Rates and spatial patterns of erosion in river bank was analysed by O'Neal and Pizzuto (2010). Aeolian beach sand transport was monitoring by Lindenbergh et al. (2011). Recently, Picco et al. (2013) evaluated short-term morphological changes in the riverbed by DoD (difference of DEMs).

The aim of this research is to generate a methodology to automatically evaluate morphological changes in dike landside slopes sampled by multi-temporal TLS data. The ICP algorithm (Besl and Mckay, 1992) was used to register scans from different viewpoints. Variations between successive point clouds from temporal datasets were calculated, providing a deviation map which precisely defines the morphological changes. Profile variations across the new slope from the eroded terrain due to different tests were analysed as well. Volumetric calculations of the moving masses are also significant to monitoring slope movements in a dike. Calculation of DoD was applied to analyse and quantify erosion and deposition rates with a high level of resolution. The main output of this workflow will allow local planning authorities to take decisions in the future. 


\section{MATERIALS AND METHODS}

\subsection{Experimental setup}

On an approximate $50 \mathrm{~m}$ long stretch of embankment along the river Scheldt near Schellebelle in Belgium, two tests were performed on breach initiation due to wave overtopping and overflow using respectively the $4 \mathrm{~m}$ wide simulators developed by Van der Meer (2012) and the $2 \mathrm{~m}$ wide overflow simulator developed by Delft University of Technology (Van Damme et al., 2016). The purpose of this experiment was to obtain more knowledge about initial failure and breaching processes of dikes. Overtopping is the situation in which the run-up level of waves attacking the dike on the outside slope of the dike is so high that the crest level is exceeded. The simulator releases volumes of water over the dike according to a schedule formed by a Weibull distribution applied on wave overtopping volumes. Overflow condition is when the flow is kept constant.

The embankment had a sandy core and a clay protection layer on the landside and waterside slope. The thickness of the clay protection layer varied from $60 \mathrm{~cm}$ near the toe of the slopes to approximately $30 \mathrm{~cm}$ near the top of the slopes. The slope gradient of the landside and waterside slope of the embankment were $1 / 1.7$ and the height of the embankment above polder level was $3.5 \mathrm{~m}$. The embankment crest, which consisted of a gravel road, was covered by plastic sheets to prevent erosion of the gravel. The slopes consisted of a grass cover of poor quality which contained nettles and weeds. The sides of the interest area were cordoned off with $0.6 \mathrm{~m}$ wooden boards on either side held in place by wooden pickets (Figure 1).

The overtopping and overflow simulator were placed on the waterside slope in such a way that the outflow openings of the simulators were at crest level. In the left Figure 1, the overtopping simulator is visible in yellow on top of the dike. A frequentially adjustable pump with a capacity of $400 \mathrm{~m}^{3} / \mathrm{h}$ was used to pump water from the river Scheldt into the simulators. A diesel generator provided the energy needed to operate the pumps and simulator controls. The overtopping experiments were executed for mean overtopping discharges of 1,5,10, and $25 \mathrm{l} / \mathrm{s} / \mathrm{m}$. Each test subsequently ran for 2 hours, with exception of the $1 \mathrm{l} / \mathrm{s} / \mathrm{m}$ test which was accelerated 5 times and hence lasted 24 minutes. Afterward, tests with the overflow simulator started at $10 \mathrm{l} / \mathrm{s} / \mathrm{m}$ due to limitations in the minimum allowable frequency at which the pump could be operated. Successively, 25, 50 and 85 $1 / \mathrm{s} / \mathrm{m}$ tests were performed. Each test under overflow conditions ran for 2 hours. The above water quantities were chosen in order to simulate normal storm episodes.

\subsection{Data acquisition: TLS}

A high speed laser scanner based on time-of-flight, type Leica Scan-Station C10, was used. The technical specifications are shown in Table 1.
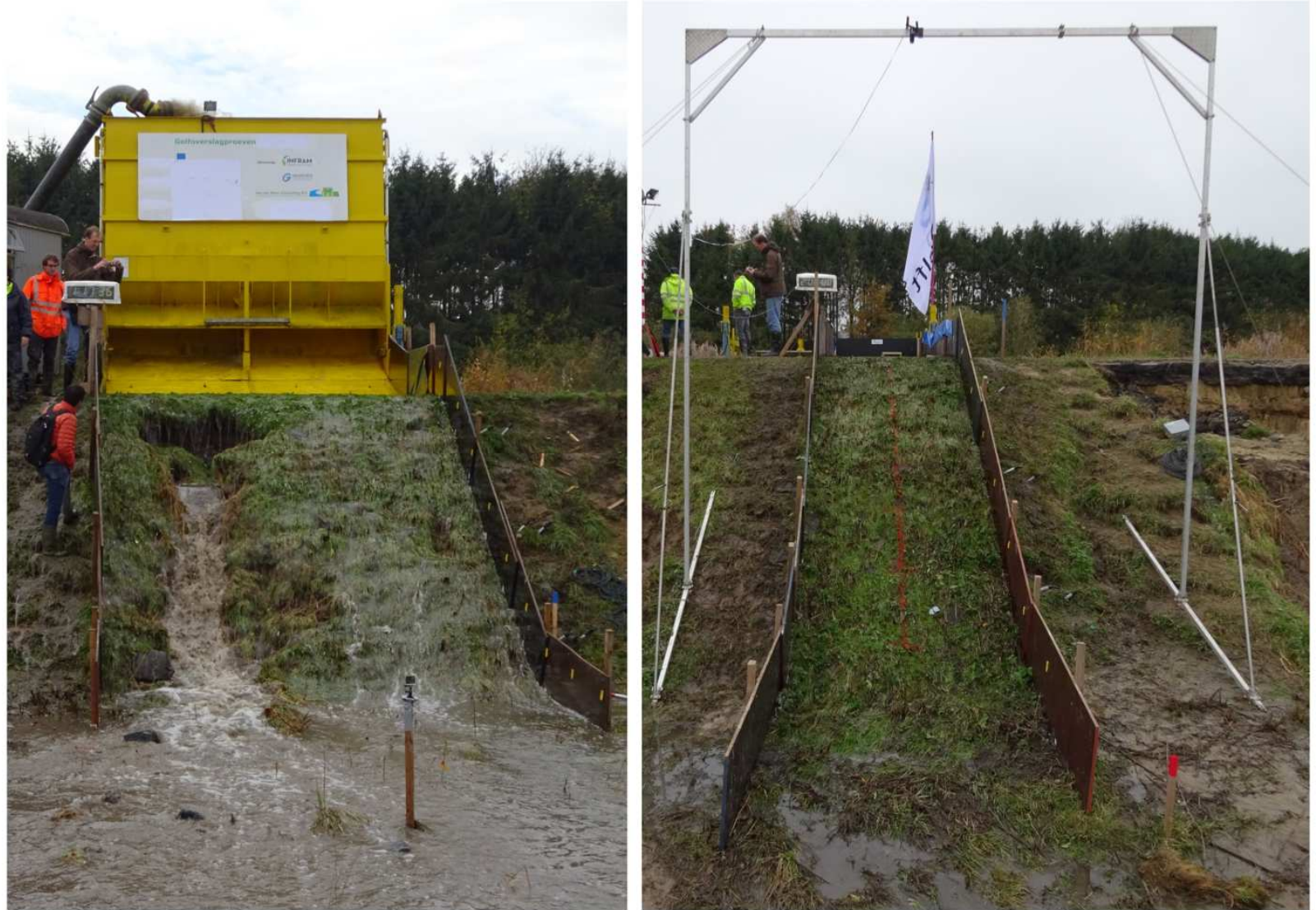

Figure 1. Overtopping (left) and overflow (right) test 
Leica Scan-Station $\mathrm{C} 10$

\begin{tabular}{ll}
\hline Position accuracy & $6 \mathrm{~mm}$ \\
Distance accuracy & $4 \mathrm{~mm}$ \\
Angle accuracy & $60 \mu \mathrm{rad}$ \\
Pulsed wavelength & $532 \mathrm{~nm}$ \\
Minimum range & $0.1 \mathrm{~m}$ \\
Scan rate & 50,000 points $/ \mathrm{s}$ \\
Maximum sample density & $<1 \mathrm{~mm}$ \\
Field of view & $360^{0} * 270^{0}$ \\
Laser class & $2($ IEC $60825-1)$ \\
\hline
\end{tabular}

Table 1. Technical specifications of Leica Scan-Station $\mathrm{C} 10$

TLS was applied at intervals of maximum 1 hour to temporally detect morphological changes. To avoid the danger posed by the experiment, the dike landside slope was scanned from a safe position in front of the study area. Scans from different viewpoints were acquired to avoid shadowing. Thereby, occlusions were evaded by creating overlaps between scans.

54 scans were acquired with different resolutions at different times in different positions.

\subsection{Data processing}

The point cloud sample may contain outliers and noisy points caused by various reasons such as backscatter from vegetation or interference effects. Such points are not regarded as samples of the actual scenarios and the first step is to filter some noise from the point cloud. Manually, isolated points or few-point clusters are removed.

The next step is the alignment of individual scans from the same epoch using the ICP algorithm (Besl and Mckay, 1992) on overlapping stable areas. Firstly, the coarse registration is done by manually picking similar points from different scans. Secondly, the ICP algorithm finds that affine transformation matrix that minimizes the distances between closet points from overlapping areas of the two scans considered. Subsequently, point clouds taken at different times were cut and filtered by a defined $3 \mathrm{D}$ polygon as a bounding region common to all scans. In order to calculate the morphological changes from these temporal datasets, the recognition of correspondences between two point clouds was required. Thereby, variations between sequential TLS datasets were calculated firstly by chamfer distance (Butt and Maragos, 1998) via an octree; and secondly, the precise distance was derived considering a local approximation of the cloud by a height function of the type $z=a x+b y+c x^{2}+d y^{2}+e x y$ (after projection of the points on a plane adjusted by least squares). As a result, a deviation map of these distance differences was provided which precisely defines site and quantity of the morphological changes.

TLS proved to be a very convenient tool to quickly create profiles across the new slope. Therefore, the collected data were used to design the new slope profile, allowing volume calculation of the required material to be excavated to stabilize the slope.

Generation of 2.5D DEMs to derive eroded volumes was the next step. Although 2.5D models allow a relevant saving in data storage, information loss should be considered caused by the necessary interpolation procedure in the grid. An optimization between accuracy and economy in computing time could be required (Aguilar et al. 2005). In this study, a grid side of $0.01 \mathrm{~m}$ by applying a 2.5 Delaunay triangulation algorithm (Golias, 1997) was chosen.

\section{EXPERIMENTAL RESULTS}

14 scans were processed taking during the breach initiation experiment with varying wave overtopping and overflow conditions with different water quantities discharged (as section 2.3 explains) in high resolution. Table 2 summarizes the number of points of the registered and filtered scans before and after each test, in a common study area of $3.8 * 8.5 \mathrm{~m}^{2}$. The initial overtopping discharge of $1 \mathrm{l} / \mathrm{s} / \mathrm{m}$ was not processed because it was considered a preparation step.

\begin{tabular}{ccrr} 
Test condition & Q(1/s/m) & \multicolumn{2}{c}{ \#No. of Points } \\
& Before & \multicolumn{1}{c}{ After } \\
\hline Overtopping & 1 & - & \multicolumn{1}{c}{-} \\
& 5 & 14,196 & 229,021 \\
& 10 & 228,877 & 11,686 \\
& 25 & 21,169 & 84,220 \\
\hline Overflow & 10 & 527,531 & 526,186 \\
& 25 & 667,568 & 663,896 \\
& 50 & 664,311 & 636,018 \\
& 85 & 635,899 & 648,040
\end{tabular}

Table 2. Number of points of the processed scans

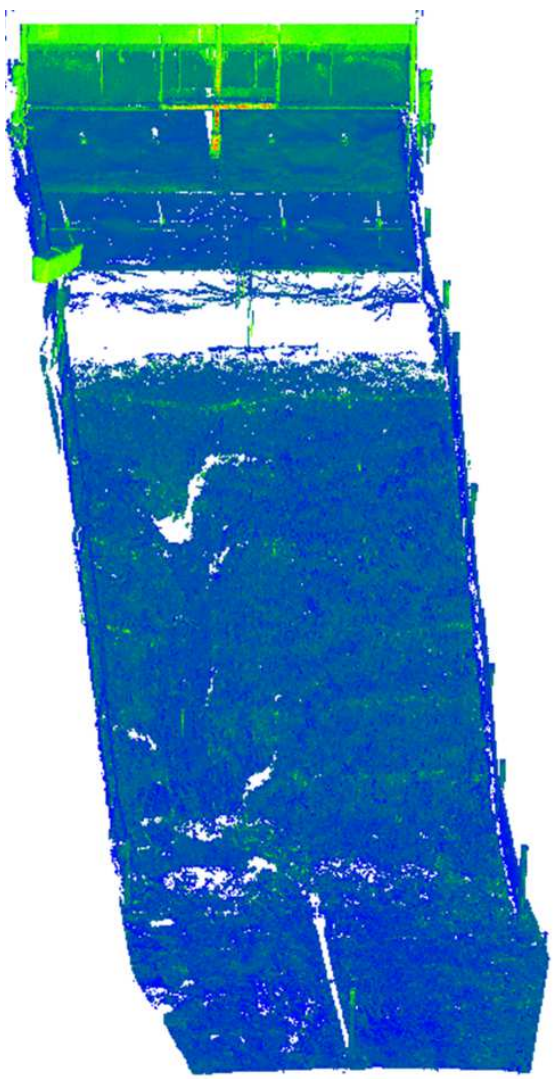

Figure 2. Dike scan 


\begin{tabular}{ccrrrr} 
Test condition & Statistics & \multicolumn{4}{c}{$\mathbf{Q}(\mathbf{l} / \mathbf{s} / \mathbf{m})$} \\
\hline Overtopping & & $\mathbf{1}$ & $\mathbf{5}$ & $\mathbf{1 0}$ & $\mathbf{2 5}$ \\
& Min & - & 0.62 & 7.00 & 2.29 \\
& Max & - & 117.89 & 450.00 & 657.33 \\
& Mean & - & 16.44 & 11.30 & 141.14 \\
& Sigma & - & 20.80 & 9.30 & 155.11 \\
\hline Overflow & & $\mathbf{1 0}$ & $\mathbf{2 5}$ & $\mathbf{5 0}$ & $\mathbf{8 5}$ \\
& Min & 0.39 & 0.59 & 0.39 & 0.46 \\
& Max & 15.44 & 15.73 & 18.85 & 27.51 \\
& Mean & 4.82 & 5.54 & 5.36 & 6.47 \\
& Sigma & 3.43 & 3.42 & 4.13 & 5.64
\end{tabular}

Table 3. Statistical parameters of the deviation maps in $\mathrm{mm}$

The variations in the number of points mostly depend on shadows generated by the vegetal cover and the reflectance change of the cover due to variations in wetness, compare Figure 1. There are many other factors which affect to the numbers of points acquired by TLS, such as atmospheric conditions (Hejbudzka et el., 2009). Figure 2 shows one scan with zones of no data due to occlusions, corresponding to the left image in Figure 1.

The following step is to generate deviation maps, comparing TLS point clouds from before and after each indicated test over the test area of $3.8 * 8.5 \mathrm{~m}^{2}$. Table 3 summarizes the main statistical parameters $(\mathrm{mm})$ derived from these deviation maps: minimum distance at the $95 \%$ probability interval ( $\mathrm{min}$ ), maximum distance at the $95 \%$ probability interval (max), mean distance at the 95\% probability interval (mean), standard deviation at the $95 \%$ probability interval (sigma).

In accordance with Table 3 and contrary to expectations, damage to the grass cover was negligible at overflow conditions, being the mean around $5 \mathrm{~mm}$. Due to these results, a detailed analysis was carried out under overtopping conditions focusing on the affected area. Table 3 shows that mean change is not increasing with water load. An explication could be the terrain geology. Figure 3 shows deviation maps coloured according to height dissimilarities and longitudinal profile variations. These results represent morphological changes along the dike landside slope, achieved for each overtopping test. Due to shadow effects and changes in wetness, there are zones with no data and variations in point density. This was the reason to establish as principal point cloud, the cloud with more numbers of points of both; and to compare only the points between dataset within a range of $8 \mathrm{~mm}$ in vertical distance. The line to calculate the longitudinal profile has been chosen according to have data and changes in the points. The volume of eroded material was calculated by subtracting each $2.5 \mathrm{D}$ correlative model (DoD) from the point cloud (Table 4). In this study, the grid has a cell size of $0.01 \mathrm{~m}$ in order to warrantee precision. Accordingly, we are able to quantify the eroded material coming from the impact on the terrain induced by wave overtopping which caused the dike failure in a few minutes in normal storm scenarios $(\mathrm{Q}=$ $25 \mathrm{l} / \mathrm{s} / \mathrm{m})$ in $1.24 \mathrm{~m}^{3}$.

\begin{tabular}{cc}
$\mathbf{Q}(\mathbf{l} / \mathbf{s} / \mathbf{m})$ & Eroded volume $\left(\mathbf{m}^{\mathbf{3}}\right)$ \\
\hline 1 & - \\
5 & 0.2030 \\
10 & 0.1410 \\
25 & 1.2366
\end{tabular}

Table 4. Eroded volume $\left(\mathrm{m}^{3}\right)$ during wave overtopping by DoD

\section{CONCLUSIONS}

A method to automatically evaluate morphological changes along a dike landside slope by multi-temporal TLS data has been presented here. TLS technology offers high accuracy and temporal and spatial resolution with a prudent cost. A full scale test along a dike landside slope by overtopping and overflow conditions was performed. The probability of non-scanned zones caused by shadowing effect and overhanging zones was minimized due to the proximity to the study area and the possibility of scanning from different angles.

The results show that TLS provides good applications in emergency situations to rapidly estimate morphological changes, including data acquisition, treatment and interpretation within a few days.

The main limitations associated with TLS data acquisition and processing are reflectance, vegetation and site accessibility. Specifically, the material reflectance influences on the measure accuracy and resolution. Vegetation and site accessibility can generate shadowing, which can be an interpretation problem.

Future works will be addressed the full waveform and intensity of the back-scattered laser pulse certainly providing information on saturation of soils for stability analysis. Another future study will be the discussion of TLS accuracy which affects the analysis of terrain slopes prior to failure by showing small displacements, as well as deriving local erosion rates. 


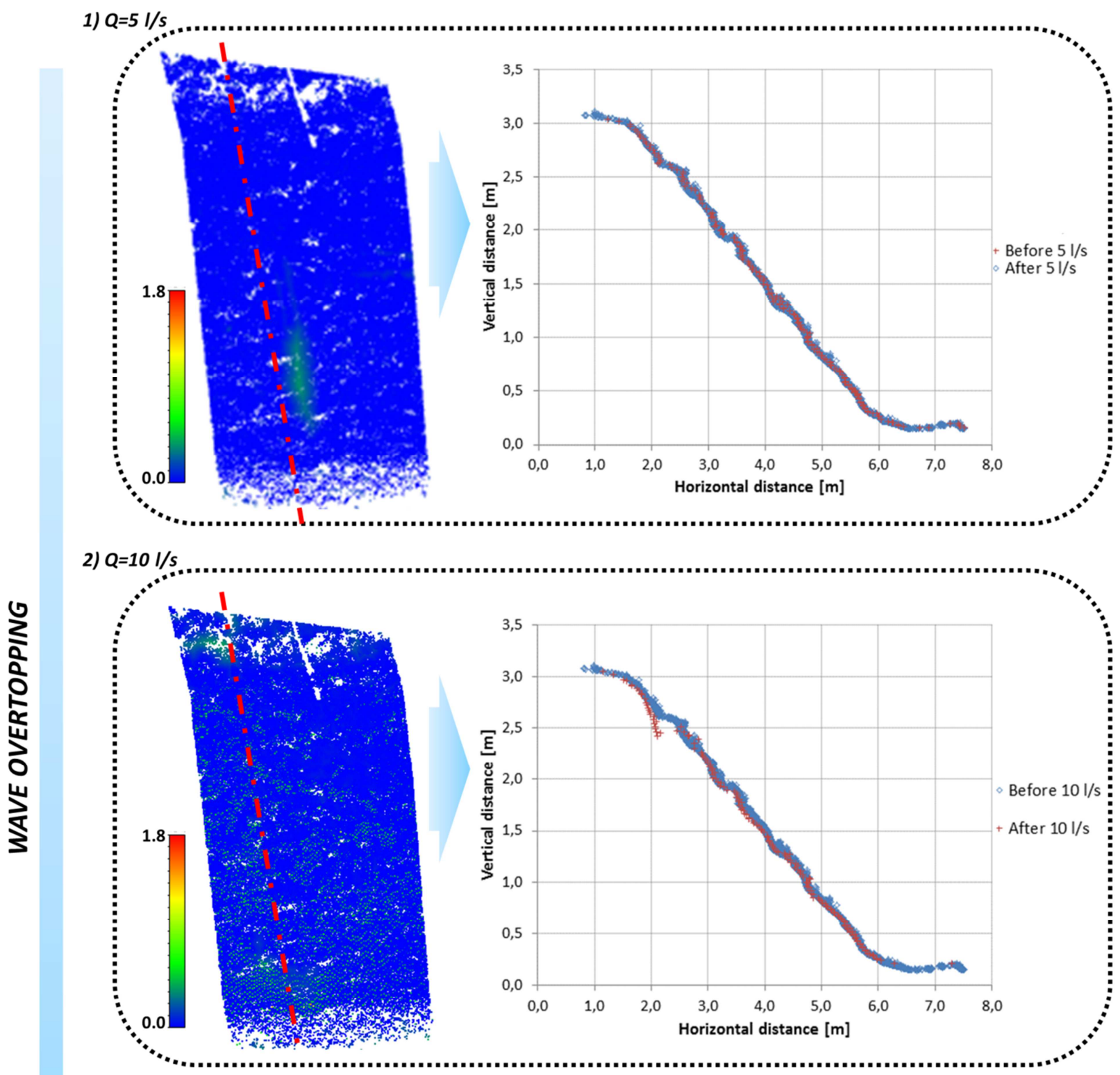

3) $Q=25 \mathrm{l} / \mathrm{s}$

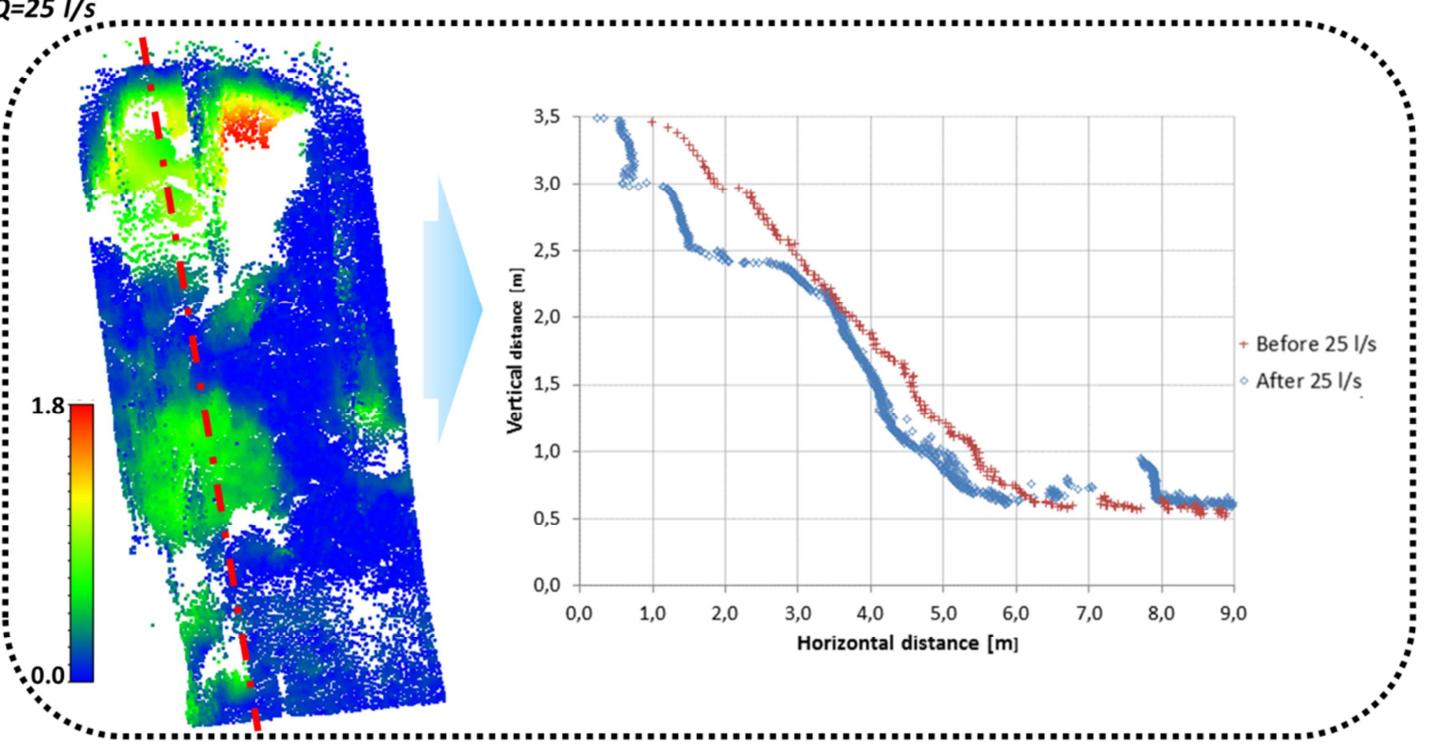

Figure 3. Deviation maps (m) and longitudinal profile variations (m) in the study area during wave overtopping 


\section{ACKNOWLEDGEMENTS}

The full scale experiment was performed by Flanders Hydraulic Research, Infram B.V. and Delft University of Technology as part of the SAFElevee project. Furthermore, it was made possible due to funding from Flanders Hydraulics Research, STW, and the Delft Infrastructure and Mobility Initiative DIMI. The research is partly funded by the FP7 project IQmulus (FP7-ICT2011-318787), aiming at the design and implementation of a high volume fusion and analysis Platform for geospatial point clouds, coverages and volumetric data sets.

\section{REFERENCES}

Aguilar, F. J., Agüera, F., Aguilar, M. A., \& Carvajal, F. (2005). Effects of terrain morphology, sampling density, and interpolation methods on grid DEM accuracy. Photogrammetric Engineering \& Remote Sensing, 71(7), 805-816.

Aguilar, M. A., Aguilar, F. J., \& Negreiros, J. (2009). Off-the-shelf laser scanning and close-range digital photogrammetry for measuring agricultural soils microrelief. Biosystems engineering, 103(4), 504-517.

Besl, P. J., \& McKay, N. D. (1992, April). Method for registration of 3-D shapes. In Robotics-DL tentative (pp. 586-606). International Society for Optics and Photonics.

Butt, M. A., \& Maragos, P. (1998). Optimum design of chamfer distance transforms. Image Processing, IEEE Transactions on, 7(10), 1477-1484.

Caelli, T., Osman, E., \& West, G. (1998). 3D shape matching and inspection using geometric features and relational learning. Computer Vision and Image Understanding, 72(3), 340-350.

Cignoni, P., Rocchini, C., \& Scopigno, R. (1998). Metro: measuring error on simplified surfaces. In Computer Graphics Forum (Vol. 17, No. 2, pp. 167-174). Blackwell Publishers.

Hejbudzka, K., Lindenbergh, R. C., Soudarissanane, S. S., \& Humme, A. (2010). Influence of atmospheric conditions on the range distance and number of returned points in Leica Scanstation 2 point clouds. In Proceedings ISPRS Commission V Mid-Term Symposium' Close Range Image Measurement Techniques', Newcastle upon Tyne, UK, 21-24 June 2010; IAPRS, XXXVIII (5), 2010.
Jaboyedoff, M., Demers, D., Locat, J., Locat, A., Locat, P., Oppikofer, T., Robitaille, D., \& Turmel, D. (2009). Use of terrestrial laser scanning for the characterization of retrogressive landslides in sensitive clay and rotational landslides in river banks. Canadian Geotechnical Journal, 46(12), 1379-1390.

Lindenbergh, R. C., Soudarissanane, S. S., De Vries, S., Gorte, B. G. H., \& De Schipper, M. A. (2011), Aeolian Beach Sand Transport Monitored by Terrestrial Laser Scanning. The Photogrammetric Record, 26: 384-399. doi: 10.1111/j.1477-9730.2011.00659.x.

O'Neal, M. A., \& Pizzuto, J. E. (2011). The rates and spatial patterns of annual riverbank erosion revealed through terrestrial laser-scanner surveys of the South River, Virginia. Earth Surface Processes and Landforms, 36(5), 695-701.

Picco, L., Mao, L., Cavalli, M., Buzzi, E., Rainato, R., \& Lenzi, M. A. (2013). Evaluating short-term morphological changes in a gravel-bed braided river using terrestrial laser scanner. Geomorphology, 201, 323334.

Rosser, N. J., Petley, D. N., Lim, M., Dunning, S. A., \& Allison, R. J. (2005). Terrestrial laser scanning for monitoring the process of hard rock coastal cliff erosion. Quarterly Journal of Engineering Geology and Hydrogeology, 38(4), 363-375.

Sutton, M. A., Orteu, J. J., \& Schreier, H. (2009). Image correlation for shape, motion and deformation measurements: basic concepts, theory and applications. Springer Science \& Business Media.

Teza, G., Galgaro, A., Zaltron, N., \& Genevois, R. (2007). Terrestrial laser scanner to detect landslide displacement fields: a new approach. International Journal of Remote Sensing, 28(16), 3425-3446.

Ujike, K., \& Takagi, M. (2004). Measurement of landslide displacement by object extraction with ground based portable laser scanner. In Proceedings of the 25th Asian Conference on Remote Sensing.

Van Damme, M., Ponsioen, L., \& Herrero-Huerta, M. (2016). Comparing overflow and wave-overtopping induced breach initiation mechanisms in an embankment breach experiment. FLoodrisk2016 Proceedings. In preparation.

Van der Meer, J., Provoost, Y., \& Steendam, G. J. (2012). The wave run-up simulator, theory and first pilot test. Coastal Engineering Proceedings, 1(33), 65. 